\title{
Multicentre early experience with totally subcutaneous cardioverter-defibrillators in Poland
}

\author{
Krzysztof Kaczmarek ${ }^{1}$, Maciej Kempa², Marcin Grabowski, Mateusz Tajstra', Adam Sokal ${ }^{5}$, \\ Iwona Cygankiewicz', Radosław Zwoliński ${ }^{6}$, Marcin Michalak³ ${ }^{3}$ Michal Kowara ${ }^{3}$, Szymon Budrejko², \\ Anna Kurek ${ }^{4}$, Jerzy K. Wranicz' ${ }^{1}$, Grzegorz Raczak², Grzegorz Opolski ${ }^{3}$, Mariusz Gąsior ${ }^{4}$, \\ Oskar Kowalski ${ }^{5}$, Paweł Ptaszyński ${ }^{1}$
}

${ }^{1}$ Department of Electrocardiology, Medical University of Lodz, Lodz, Poland
2Department of Cardiology and Electrotherapy, Medical University of Gdansk,
Gdansk, Poland
${ }^{3} 1^{\text {st }}$ Chair and Department of Cardiology, Medical University of Warsaw, Warsaw, Poland
${ }^{4} 3^{\text {rd }}$ Chair and Department of Cardiology, Silesian Medical University, Katowice, Poland
${ }^{5}$ Department of Cardiology, Congenital Heart Diseases and Electrotherapy,
Sllesian Medical University, Katowice, Poland
${ }^{6}$ Department of Cardiosurgery, Medical University of Lodz, Lodz, Poland

Submitted: 31 July 2018

Accepted: 19 January 2019

Arch Med Sci 2020; 16 (4): 764-771

DOI: https://doi.org/10.5114/aoms.2019.83817

Copyright $\odot 2019$ Termedia \& Banach

\section{Abstract}

Introduction: Implantable cardioverter-defibrillators (ICD) have a strong position in the prevention of sudden death. Nowadays, the most commonly used high-energy cardiac devices are transvenous ICDs. A new technology of totally subcutaneous ICDS (S-ICD) was invented and recently introduced into clinical practice in order to reduce lead-related complications of conventional ICDs. The aim of this paper is to present early experience with this new technology implemented in a few centres in Poland.

Material and methods: Medical records of patients who had S-ICD-related interventions in Poland were retrospectively analysed.

Results: During the first year of S-ICD introduction into the Polish health system 18 patients underwent surgery connected with S-ICDs. Majority of them (17 patients) were implanted de novo. In one patient surgical revision of a device implanted abroad was performed. Most of patients (78\%) had S-ICDs implanted for secondary prevention. Inability of transvenous system implantation due to venous access obstruction or high risk of infection related with transvenous leads accounted for $83 \%$ of indications for S-ICD. Only in three patients were S-ICDs implanted due to young age and active mode of life. The implantations of S-ICDs were performed without important early or late complications. During follow-up one patient had episodes of ventricular arrhythmia successfully terminated with high-energy shocks. One patient died due to progression of heart failure.

Conclusions: S-ICD implantation procedure has been successfully and safely introduced in Polish clinical routine. Nevertheless, despite clear indications in recent ESC guidelines, this therapy is not directly reimbursed in Poland and needs individual application for refund.

Key words: sudden cardiac death, implantable cardioverter defibrillator, subcutaneous cardioverter defibrillator.

\section{Introduction}

Prevention of sudden cardiac death $(S C D)$ is one of the major problems of modern cardiology. Development and popularisation of implant-

\author{
Corresponding author: \\ Krzysztof Kaczmarek MD, PhD \\ Department \\ of Electrocardiology \\ Medical University of Lodz \\ 1/3 Sterlinga St \\ 91-425 Lodz, Poland \\ E-mail: medkrzych@yahoo.es
}


able cardioverter-defibrillators (ICD) has resulted in a breakthrough in the treatment of patients who are at high risk of SCD. Currently, ICD implantations are considered as routine procedures in cardiology departments in Europe and North America. Up to now the vast majority of high-voltage cardiac implants include a defibrillation lead placed transvenously to the right ventricle. Alternatively, epicardial defibrillation patches are applicable, but these solutions are used rarely and usually in paediatric patients or specially selected adults [1, 2]. The most important advantage of transvenous ICD (T-ICD) is relatively safe, minimally invasive surgery connected with a low complication rate. On the other hand, even rarely observed lead-dependent problems may be life-threatening (i.e. cardiac tamponade or infective endocarditis). Moreover, in selected patients, insertion of an intracardiac lead may be difficult or impossible (i.e. in the case of subclavian vein occlusion) [3-5].

Recently, a new device concept - a totally subcutaneous ICD (S-ICD) - was introduced to the medical armament against SCD. The leads of the S-ICD are implanted subcutaneously on the chest, and a pulse generator is placed on the left lateral part of the chest subcutaneously, intermuscularly, or inframuscularly (Figure 1). During the procedure, the vascular system remains untouched. The main disadvantage of S-ICD is the inability to provide permanent cardiac pacing [6, 7].

The first S-ICD implantation in Poland was performed in October 2014 in a young male adult who had an T-ICD removed and an artificial tricuspid valve implanted due to fulminant endocarditis [8].

The aim of this paper is to provide an overview of early experience with S-ICDs in Poland in order to propose solutions that could facilitate the use of this technology in accordance with Polish conditions.

\section{Material and methods}

Medical records of patients who had S-ICD-related interventions in Poland were retrospectively analysed. The data were collected between September 2014 and December 2015 and included: demography, past medical history, the course of S-ICD implantation or intervention, and further follow-up of the patients. Special attention was paid to the reason for S-ICD selection, the course of S-ICD implantation, and the incidence of device- or procedure-related complications. The data were obtained directly from physicians who took care of the patients. Diagnostic and therapeutic management was left to the discretion and medical routine of each department of cardiology. Because these procedures were novel in Poland, preparation to some of the S-ICD implantations was performed in contact with and under the su-

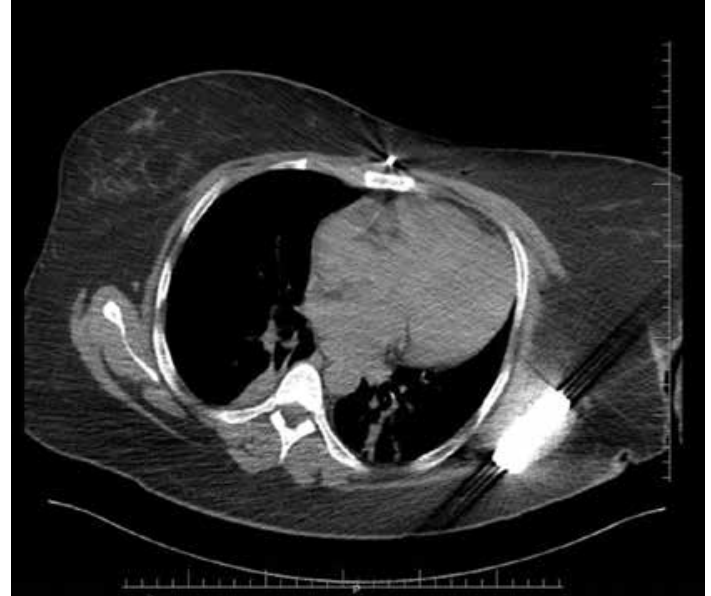

Figure 1. Computed tomography of the chest of a patient with an implanted S-ICD

pervision of experts provided by the manufacturer (Boston Scientific Co., MA, USA).

\section{Results}

\section{Patient population}

The S-ICDs were implanted in five cardiology departments of four medical centres in Poland. Each centre performed from one to eight procedures. During the study period 17 patients had an S-ICD implanted de novo and 1 patient (No. 4) underwent surgical revision of a device previously implanted abroad. The study population consisted of 10 men and 8 women, aged 19 to 71 years (mean: $44.9 \pm 15.7$ years) (Table I).

Secondary prevention of SCD was the major indication for ICD implantation (78\%). A history of ventricular fibrillation and haemodynamically instable ventricular tachycardia was revealed in 10 and four patients, respectively. Channelopathies or inherited cardiomyopathies (hypertrophic cardiomyopathy or arrhythmogenic right ventricle cardiomyopathy) were diagnosed in $50 \%$ of the patients, whereas the remaining $50 \%$ had ischaemic or dilated cardiomyopathies. Systolic dysfunction of the left ventricle was observed in 6 patients (severe dysfunction in 4 and moderate in 2 individuals). The majority of the patients (78\%) were in sinus rhythm. Atrioventricular block or bundle branch block were registered in eight patients. Permanent cardiac pacing was provided before S-ICD placement for two of them (Table II). Because the first patient had artificial tricuspid valve a pacing lead was inserted epicardially (patient no. 1). The second individual had the lead implanted transfemorally because of bilateral occlusion in the subclavian veins (patient no. 3).

Seven patients had a history of previous insertion of transvenous high-voltage cardiac devices. Five of them had received ICD and two had 
K. Kaczmarek, M. Kempa, M. Grabowski, M. Tajstra, A. Sokal, I. Cygankiewicz, R. Zwoliński, M. Michalak, M. Kowara, S. Budrejko, A. Kurek, J. K. Wranicz, G. Raczak, G. Opolski, M. Gąsior, O. Kowalski, P. Ptaszyński

Table I. Demographics and clinical characteristics of the Polish S-ICD population

\begin{tabular}{|lccccccc|}
\hline $\begin{array}{l}\text { No. } \\
\text { of patient }\end{array}$ & Sex/age & $\begin{array}{c}\text { SCD } \\
\text { prevention }\end{array}$ & Aetiology & $\begin{array}{c}\text { EF } \\
(\%)\end{array}$ & $\begin{array}{c}\text { Rhythm; conduction } \\
\text { abnormalities }\end{array}$ & Department & $\begin{array}{c}\text { S-ICD } \\
\text { surgery date }\end{array}$ \\
\hline 1 & M/28 & Secondary, VF & IVF & 60 & SR; AVB2/3 & $(1)$ & 22.09 .2014 \\
\hline 2 & F/57 & Secondary, VF & IVF & 60 & SR; AVB1 & $(2)$ & 23.09 .2014 \\
\hline 3 & F/65 & Secondary, VF & ICM & 26 & Brady AFIB, NBBB & $(1)$ & 18.12 .2014 \\
\hline $4^{*}$ & M/40 & Secondary, VF & IVF & 60 & SR; none & $(2)$ & 21.12 .2014 \\
\hline 5 & F/62 & Primary & ICM & 30 & SR; AVB1, RBBB & $(2)$ & 18.02 .2015 \\
\hline 6 & M/67 & Secondary, VF & ICM & 50 & SR; AVB1 & $(1)$ & 03.03 .2015 \\
\hline 7 & M/19 & Secondary, VF & PMC & 63 & SR; none & $(4)$ & 14.03 .2015 \\
\hline 8 & F/36 & Secondary, VF & HCM & 71 & SR; none & $(1)$ & 18.03 .2015 \\
\hline 9 & M/52 & Secondary, VT & DCM & 45 & SR; none & $(4)$ & 24.03 .2015 \\
\hline 10 & M/36 & Secondary, VF & CHD & 55 & AFIB; none & $(3)$ & 16.09 .2015 \\
\hline 11 & M/25 & Primary & BS & 65 & SR; none & $(1)$ & 25.06 .2015 \\
\hline 12 & F/32 & Secondary, VF & LQTS & 58 & SR; none & $(1)$ & 15.07 .2015 \\
\hline 13 & M/61 & Primary & ICM & 30 & AFIB; none & $(3)$ & 20.07 .2015 \\
\hline 14 & M/62 & Secondary, VF & ICM & 45 & AFIB; NBBB & $(3)$ & 04.09 .2015 \\
\hline 15 & F/67 & Secondary, VF & DCM & 28 & SR; LBBB & $(5)$ & 15.10 .2015 \\
\hline 16 & F/28 & Primary & HCM & 69 & SR; none & $(1)$ & 21.10 .2015 \\
\hline 17 & F/34 & Secondary, VT & ARVD & 50 & SR; none & $(2)$ & 22.10 .2015 \\
\hline 18 & M/38 & Secondary, VT & DCM & 50 & SR; none & $(1)$ & 21.12 .2015 \\
\hline
\end{tabular}

F-female, M - male, VF - ventricular fibrillation, VT - ventricular tachycardia, IVF - idiopathic VF, ICM - ischemic cardiomyopathy, PMC - postmyocarditis cardiomyopathy, DCM - infective dilated cardiomyopathy, HCM - hypertrophic cardiomyopathy, CHD - congenital heart disease, BS - Brugada syndrome, LQTS - long QT syndrome, ARVD - arrhythmogenic right ventricle dysplasia, SR - sinus rhythm, $A F I B$ - atrial fibrillation, $A V B 1 / 2 / 3$ - atrioventricular block $1^{\text {st }} / 2^{\text {nd }} / 3^{\text {rd }}$ degree, $R B B B / L B B B / N B B B$ - right/left/non-specific bundle branch block (1) - Department of Electrocardiology, Medical University of Lodz, (2) - Department of Cardiology and Electrotherapy, Medical University of Gdansk, (3) - Department of Cardiology, Medical University of Warsaw, (4) - $3^{\text {rd }}$ Chair and Department of Cardiology, Silesian Centre for Heart Diseases, (5) - Department of Cardiology Chair of Cardiology, Congenital Heart Disease and Electrotherapy, Silesian Centre for Heart Diseases ${ }^{*}$ Patient implanted abroad, whose S-ICD was revised surgically in Poland.

Table II. History of T-ICD complications and indications for S-ICD implantation

\begin{tabular}{|c|c|c|c|c|c|c|c|}
\hline $\begin{array}{l}\text { No. } \\
\text { of patient }\end{array}$ & $\begin{array}{c}\text { History } \\
\text { of T-ICD } \\
\text { implant (no.) }\end{array}$ & $\begin{array}{l}\text { T-ICD } \\
\text { malfun- } \\
\text { ction }\end{array}$ & $\begin{array}{c}\text { History } \\
\text { of } \\
\text { CDRIE }\end{array}$ & $\begin{array}{c}\text { T-ICD } \\
\text { explanted }\end{array}$ & $\begin{array}{l}\text { High } \\
\text { risk } \\
\text { of CDRIE }\end{array}$ & $\begin{array}{l}\text { Obstruction } \\
\text { in venous } \\
\text { access }\end{array}$ & $\begin{array}{l}\text { Reason } \\
\text { for } S-I C D\end{array}$ \\
\hline 1 & Yes (1) & No & Yes & Yes $^{* *}$ & Yes & Yes, total: TVR & VAO, risk of CDRIE \\
\hline 2 & No & - & - & - & Yes & Yes, two-sided & VAO, risk of CDRIE \\
\hline 3 & Yes (3) & No & Yes & Yes $^{* * *}$ & Yes & Yes, two-sided & VAO, risk of CDRIE \\
\hline $4^{*}$ & No & - & - & - & No & No & Age \\
\hline 5 & No & - & - & - & Yes & Yes, two-sided & VAO, risk of CDRIE \\
\hline 6 & Yes (2) & No & Yes & Yes & Yes & Yes, one-sided & VAO, risk of CDRIE \\
\hline 7 & No & - & - & - & No & No & Age \\
\hline 8 & Yes (1) & Yes & No & No & No & Yes, one-sided & VAO \\
\hline 9 & No & - & - & - & No & No & RV perforation \\
\hline 10 & No & - & - & - & No & Yes, two-sided & VAO \\
\hline 11 & No & - & - & - & No & No & Age \\
\hline 12 & No & - & - & - & Yes & No & Risk of CDRIE \\
\hline 13 & Yes (1) & No & Yes & Yes & Yes & No & Risk of CDRIE \\
\hline 14 & No & - & - & - & Yes & No & Risk of CDRIE \\
\hline 15 & Yes (2) & No & Yes & Yes & Yes & No & Risk of CDRIE \\
\hline 16 & No & - & - & - & No & No & Age \\
\hline 17 & Yes (2) & No & Yes & Yes & Yes & Yes, one-sided & VAO, Risk of CDRIE \\
\hline 18 & No & - & - & - & Yes & No & Risk of CDRIE \\
\hline
\end{tabular}

$T / S-I C D$ - transvenous/subcutaneous implantable cardioverter-defibrillator, CDRIE - cardiac device-related infective endocarditis, TVR tricuspid valve replacement (mechanical valve), VAO - venous access obstruction, RV - right ventricle, (1...3) - number of T-ICD placements ${ }^{*}$ Patient implanted abroad, whose S-ICD was revised surgically in Poland, ${ }^{* *}$ patient with epicardial permanent pacemaker, ${ }^{* * *}$ patient with permanent pacemaker implanted via right femoral vein. 
undergone cardiac resynchronisation therapy (CRT). Transvenous systems were removed in 6 of these patients due to cardiac device-related infective endocarditis (CDRIE). In 4 patients the transvenous systems were inserted more than once. The remaining 1 (female patient no. 8) had a damaged defibrillation lead, but, surprisingly, she refused to have the malfunctioning system extracted. After the transvenous systems explantation the majority of these patients had venous access obstruction. The problems with venous access to the right ventricle through the superior vena cava was identified in a further 2 patients (no. 1 and 10). The first patient had an artificial tricuspid valve implanted and the second one a history of intensive systemic chemotherapy and chest radiotherapy (Table II). In all patients with CRT indication further implantation attempts of transvenous systems were abandoned due to post-extraction two-sided obstruction in venous access.

During the study period only in three individuals with implantations performed in Poland was S-ICD selected due to their young age (all below 30 years old). There were no other arguments in favour of totally subcutaneous systems in these patients (Figure 2). The rest of the population received S-ICDs because of venous access obstruction and/or high risk of CDRIE. The high risk of infectious complications resulted from previous history of CDRIE or/and haemodialysis via permanent venous catheter (patients no. 5, 12, 14).

Electrocardiographic screening recommended by the manufacturer was performed in all patients. The screening failed only in one individual (no. 8), but initial positions of leads were subsequently modified, which resulted in positive rescreening. The rest of the patients passed the screening successfully. Eventually, patient no. 8 had an S-ICD system implanted in a modified location, which is described elsewhere [9].

\section{Surgical procedure}

The vast majority of the patients had an S-ICD implanted de novo. Only in one patient (no. 4) was the surgery composed of repositioning of a pulse generator that had been previously implanted abroad. All procedures were performed under general anaesthesia by 2-4 physicians, typically as a team of electrophysiologists or a team of electrophysiologists and cardiac surgeons. Patient no. 4 was operated on by two plastic surgeons with an electrophysiologist present as a consultant. X-ray imaging was used for guidance of the position of S-ICD components in 11 implantations (61\%). The three-incision technique was preferred in the majority of centres. Only two patients (no. 16 and 18) in one centre were operated with

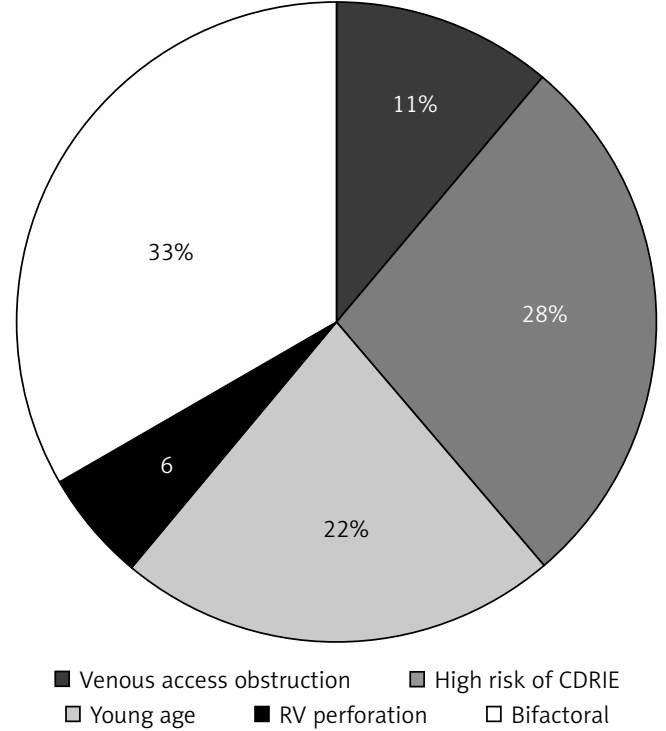

Figure 2. Indications for S-ICD implantation

two incisions. The pulse generators were placed preferably in intermuscular pocket (61\% patients). In 3 patients the devices were implanted subcutaneously. Each procedure included defibrillator testing (DFT). The detection of induced ventricular arrhythmia was successful in every implanted patient. The first high-energy shocks of 65 joules with standard vector applied during the DFTs were effective in all patients but one. This subject was successfully converted from ventricular fibrillation with 65-joule shock with reversed vector in a subsequent DFT attempt. The procedures of de novo S-ICD implantation lasted approximately one to $2 \mathrm{~h}$ (84 $\pm 14 \mathrm{~min})$. All procedures were performed successfully with no periprocedural complications (Table III).

\section{Follow-up}

The follow-up period varied from one to 15 months (mean: 8 months). One patient (no. 3) died due to heart failure progression. Two episodes of ventricular arrhythmia were registered in one patient (no. 9) and appropriately treated by S-ICD. Early post-procedural wound healing was normal in all individuals. However, one patient (no. 10) had a device surgically revised due to incipient erosion four months after initial S-ICD implantation. No further device-related complications were recorded. All patients accepted the device with no major complaints. The check-ups of the devices revealed no abnormalities in electrical parameters of implanted systems. In the majority of the cases the costs of the devices and surgery were covered by the Public Health System following the individual application for reimbursement. A few implants of S-ICDs were covered by the hospitals' own funds. 
K. Kaczmarek, M. Kempa, M. Grabowski, M. Tajstra, A. Sokal, I. Cygankiewicz, R. Zwoliński, M. Michalak, M. Kowara, S. Budrejko, A. Kurek, J. K. Wranicz, G. Raczak, G. Opolski, M. Gąsior, O. Kowalski, P. Ptaszyński

Table III. S-ICD implantation - surgery details

\begin{tabular}{|c|c|c|c|c|c|c|c|c|}
\hline $\begin{array}{l}\text { No. } \\
\text { of patient }\end{array}$ & $\begin{array}{l}\text { Anae- } \\
\text { sthesia }\end{array}$ & $\begin{array}{l}\text { Physi- } \\
\text { cians }\end{array}$ & X-rays & S-ICD pocket & $\begin{array}{l}\text { Inci- } \\
\text { sions }\end{array}$ & S-ICD Test & Time* & $\begin{array}{l}\text { Compli- } \\
\text { cations }\end{array}$ \\
\hline 1 & General & 2: EP, CS & Yes & Intermuscular & 3 & $1^{\text {st }}$ Effective (65J) & 90 & None \\
\hline 2 & General & 2: EP & No & Subcutaneous & 3 & $1^{\text {st }}$ Effective (65J) & 60 & None \\
\hline 3 & General & 2: EP, CS & Yes & Intermuscular & 3 & $1^{\text {st }}$ Effective (65J) & 90 & None \\
\hline $4^{\star *}$ & General & 2: PS & No & Intermuscular & - & - & 90 & None \\
\hline 5 & General & 2: EP & No & Subcutaneous & 3 & $1^{\text {st }}$ Effective (65J) & 60 & None \\
\hline 6 & General & 2: EP, CS & Yes & Intermuscular & 3 & $1^{\text {st }}$ Effective (65J) & 80 & None \\
\hline 7 & General & 4: 2EP, 2 CS & Yes & Intermuscular & 3 & $1^{\text {st }}$ Effective (65J) & 80 & None \\
\hline 8 & General & 2: EP, CS & Yes & Intermuscular & 3 & $1^{\text {st }}$ Effective (65J) & 110 & None \\
\hline 9 & General & 4: 2EP, 2CS & Yes & Intermuscular & 3 & $1^{\text {st }}$ Effective (65J) & 90 & None \\
\hline 10 & General & 2: EP & Yes & Subcutaneous & 3 & $1^{\text {st }}$ Effective (65J) & ND & None \\
\hline 11 & General & 2: EP & Yes & Intermuscular & 3 & $2^{\text {nd }}$ Effective (65J rev.) & 70 & None \\
\hline 12 & General & 2: EP, CS & Yes & Intermuscular & 3 & $1^{\text {st }}$ Effective (65J) & 90 & None \\
\hline 13 & General & 2: EP & Yes & Intermuscular & 3 & $1^{\text {st }}$ Effective (65J) & ND & None \\
\hline 14 & General & 2: EP & Yes & Subcutaneous & 3 & $1^{\text {st }}$ Effective (65J) & ND & None \\
\hline 15 & General & 3: EP, CS, GS & Yes & Inframuscular & 3 & $1^{\text {st }}$ Effective (65J) & 100 & None \\
\hline 16 & General & 2: EP & Yes & Intermuscular & 2 & $1^{\text {st }}$ Effective (65J) & 80 & None \\
\hline 17 & General & 2: EP & No & Subcutaneous & 3 & $1^{\text {st }}$ Effective (65J) & 80 & None \\
\hline 18 & General & 2: EP & Yes & Intermuscular & 2 & $1^{\text {st }}$ Effective (65J) & 90 & None \\
\hline
\end{tabular}

EP - electrophysiologist, CS - cardiac surgeon, PS - plastic surgeon, GS - general surgeon, rev. - reversed, ND - no data provided. ${ }^{\star} T i m e$ approximated to $10 \mathrm{~min}$, ** patient implanted abroad, whose S-ICD was revised surgically in Poland.

\section{Discussion}

Implantable cardioverter-defibrillators play an important part in the reduction of SCDs in selected populations [1, 10]. Even though transvenous high-voltage cardiac devices are still a standard therapy in arrhythmic death prevention, they pose a certain risk of complications. The intracardiac leads are the weakest part of these systems. Some lead-related complications are potentially lethal, i.e. heart perforation, cardiac device-related infective endocarditis, or haemothorax $[3,11$, 12]. Totally subcutaneous ICDs were developed to overcome the problems connected with the leads implanted to the heart $[6,7]$. Ironically, the main advantage of S-ICDs, the lack of intracardiac leads, constitutes its major weakness, defined as the inability to perform permanent cardiac pacing. This system delivers only post-shock bradycardia pacing at 50 beats per minute for no longer than $30 \mathrm{~s}$. Unfortunately, antitachycardia pacing is not provided by S-ICD either, which is an important limitation in certain populations of patients. Moreover, although the pulse generator in subcutaneous systems is substantially bigger and heavier than in the case of T-ICDs, its battery lasts for significantly less time (approximately 7 years) [13]. The efficacy of S-ICD is supported by a growing body of scientific evidence every year [14-19].

Our study population, similarly to Austrian, Swedish, and German cohorts [14, 20], was rel- atively young (44 \pm 15.7 years). Dutch patients [21, 22] were older (50 \pm 14 years), whereas those implanted in the United Kingdom were younger (median: 33 years) [23]. These differences were probably caused by different selection of the patients. Olde Nordkamp et al. recruited patients following three main criteria: patient preference, complication of T-ICD, or when the physician deemed S-ICD as more appropriate [21]. Polish centres referred to S-ICD such patients in whom implantation of a T-ICD was risky or even impossible. There were only a few patients selected due to other reasons, mainly age. As was suggested by other authors, young patients may be suitable candidates for S-ICD because of higher risk of transvenous lead fractures $[20,23,24]$.

A distribution of underlying cardiac aetiologies varies significantly between authors. Coronary artery disease and dilated cardiomyopathy were usually the main cardiac pathologies (up to 85\%) [21-23], which contrasts with our population in which these aetiologies were identified in less than half of the patients (47\%). Primary electrical disease was diagnosed in one third of the study group, which was relatively similar to early Dutch (36\%), Austrian (37\%), and British (43\%) experience but considerably different from what was reported in large studies. In combined analysis of the IDE study and EFFORTLESS registry [15] the incidence of primary electrical disease was only 
$15 \%$, while ischaemic and dilated cardiomyopathy were diagnosed in almost $70 \%$ of patients.

Papers describing early experience with S-ICD reported that primary prophylaxis of SCD was an indication for high-voltage systems usually in more than half of the patients (50-67\%) [21-23, 25]. The pooled analysis of IDE and the EFFORTLESS registry revealed that $70 \%$ of their group were implanted in primary prophylaxis of SCD [15]. A predominance of patients implanted in secondary prevention of SCD was reported by Khazen et al. (59\%) [20]; however, it was still lower than in our population, in which the indication for a high-voltage device reached almost $80 \%$. Again, a difference in the selection for S-ICD between the aforementioned centres is the most likely explanation of the observed dissimilarities. Our study confirms what was suggested from low-numbered survey data (only 8 Polish patients with S-ICDs), i.e. that indications for S-ICD in Poland differ from those in other European countries [26].

Implantation of an S-ICD is technically a novel procedure for cardiologists, thus new surgical skills are needed to be mastered [6, 23, 25, 27]. All procedures were successfully performed in our population, which is consistent with the high success rate of S-ICD implantation reported by other authors $[15,28]$. The procedures performed in Poland were usually done by electrophysiologists, but in some centres the first few implantations were supported by cardiac or general surgeons. One surgery, which involved repositioning of devices previously implanted too superficially, was performed by plastic surgeons. Dabiri Abkenari et al. also reported support of a surgeon for the first procedure [22]. In our group each totally subcutaneous system was implanted under general anaesthesia. The largest study to report surgical details is the EFFORTLESS registry (432 patients), in which general anaesthesia was used in $63 \%$ of patients [29]. The Dutch experience [21] reported that general anaesthesia was done even less frequently $(47 \%)$, and in one centre in the Netherlands procedures were routinely done under local anaesthesia combined with conscious sedation (97\%) [22]. In the Polish group S-ICDs were mainly implanted intermuscularly (80\%) and with the three-incision technique (85\%). Only 2 patients in a centre with the highest number of S-ICD implants were implanted with 2 incisions. Even though surgical approaches for S-ICD implantation seem to be comparable [25], some authors point out that the two-incision technique and intermuscular generator placement may be more favourable [27, 30]. Interestingly, in further experience published by one of the Polish centres the subcutaneous generator placement used at the beginning was then abandoned in favour of an intermuscular ap- proach [31]. Overall implantation time (mean: 84 $\pm 14 \mathrm{~min}$ ) was within the limits reported by others (mean: 45-101 min) [22, 25, 28].

There was relatively low complication rate in our group. Only one surgery due to incipient pocket erosion was performed (5.5\%), but no S-ICD system-related infection was noted. Other authors reported that the frequency of complications related to the device or the procedure accounted for approximately $10 \%$ [15]. Registries published in the Netherlands and the United Kingdom showed a significantly higher incidence of re-operation (14\% and $17 \%$, respectively). Device infection leading to S-ICD system removal or revision was reported in $6-9 \%[21,23]$. Similarly, $5 \%$ of complications requiring surgery was documented by Khazen et al. [20]. An explanation for the relatively lower rate of S-ICD-related infections in the Polish group could lie firstly in strict antiseptic preparation and secondly in intensive antibiotic periprocedural prophylaxis, including administration of intravenous vancomycin or prolonged course of standard antimicrobial agents. Additionally, in many Polish centres the first few procedures were performed in hybrid rooms with the assistance of cardiac surgeons. Such intensive antimicrobial treatment might have resulted from a high number of patients with elevated risk of infection (61\%). Precise data regarding particular measures that were undertaken in each centre were not collected; therefore, any exact interpretation of this observation cannot be made. The observation of the low rate of infectious complications should be interpreted carefully due to the limited sample size and relatively short follow up.

Only 1 (5\%) patient from our group suffered from two appropriate shocks. There were no inappropriate shocks recorded. Lambiase and Srinivasan's summary of early experience with S-ICD from six publications showed appropriate high-energy shocks observed in $5-12 \%$ of patients [28]. These data remain in agreement with our observation, especially if the length of follow-up is taken into account. On the other hand, $5-15 \%$ of patients with S-ICDs received inappropriate shocks $[15,28]$; therefore, not even one such event in the Polish population contrasts with these data. However, when compared with a similar group of patients reported by German centres [31], in which inappropriate shocks were noted in $5 \%$ of 40 individuals in analogous follow-up period, statistically these events could not have happened in our population. Additionally, the majority of Polish patients had a history of previous serious complications. Therefore, it is highly probable that these patients received intensive antiarrhythmic therapy, which could have reduced the number of arrhythmic events substantially. Moreover, all our 
K. Kaczmarek, M. Kempa, M. Grabowski, M. Tajstra, A. Sokal, I. Cygankiewicz, R. Zwoliński, M. Michalak, M. Kowara, S. Budrejko, A. Kurek, J. K. Wranicz, G. Raczak, G. Opolski, M. Gąsior, O. Kowalski, P. Ptaszyński

patients' devices were programmed in a two-zone fashion that has been proven to decrease the incidence of inappropriate shocks [11].

In the first year of the S-ICD technology introduction to Poland five cardiology centres reported S-ICD surgery. On average, each department performed 3.8 procedures, which could be compared to median five implants per centre in the initial 2-year experience in the United Kingdom [23]; however, the figure is far lower than in the report published in the Netherlands, where almost 120 implants were performed in four centres [21]. Two Polish centres published longer experience with SICD, reporting three and four S-ICD procedures in the first year, then seven and eight further implants, respectively, in the following 2 years [32-34]. These data show that S-ICD technology is still applied with important limitation in Poland without reaching the recommended level of 15 procedures [21] even in the leading centres. The major factor that narrows the application of this technology is the restriction of reimbursement within the Public Health System. S-ICD technology is not included in healthcare services guaranteed by the Public Health System in Poland. Therefore, to get reimbursement for each individual patient an application with detailed explanation of medical conditions of the recipient had to be sent to the local representatives of the state authorities.

The data presented herein as well as the data gathered in other leading cardiology centres in Poland served as the input for the experts' opinion paper on S-ICD application in prevention of SCD in Poland [35].

The main limitations of the study include: 1) low number of patients; 2 ) retrospective character of analysis; 3) relatively short follow-up period; and 4) some missing data.

In conclusion, totally subcutaneous implantable cardioverters-defibrillators were successfully and safely implanted in Polish cardiology units. Initially the procedures were supported by surgeons, which produced excellent results. No important complications were observed during lengthy follow-up. The main limiting factors of this technology in Poland include its relatively high price compared with transvenous systems and a lack of direct reimbursement from the National Health System.

\section{Conflict of interest}

Krzysztof Kaczmarek, Maciej Kempa, Marcin Grabowski, Oskar Kowalski, Adam Sokal and Paweł Ptaszyński received consultation fee from Boston Scientific Company. Other authors declare no conflict of interest.

\section{References}

1. Priori SG, Blomström-Lundqvist C, Mazzanti A, et al.; ESC Scientific Document Group. 2015 ESC Guidelines for the management of patients with ventricular arrhythmias and the prevention of sudden cardiac death: The Task Force for the Management of Patients with Ventricular Arrhythmias and the Prevention of Sudden Cardiac Death of the European Society of Cardiology (ESC). Endorsed by: Association for European Paediatric and Congenital Cardiology (AEPC). Eur Heart J 2015; 36: 2793-867.

2. Schneider AE, Burkhart HM, Ackerman MJ, Dearani JA, Wackel P, Cannon BC. Minimally invasive epicardial implantable cardioverter-defibrillator placement for infants and children: an effective alternative to the transvenous approach. Heart Rhythm 2016; 13: 1905-12.

3. Joy PS, Kumar G, Poole JE, London B, Olshansky B. Cardiac implantable electronic device infections: who is at greatest risk? Heart Rhythm 2017; 14: 839-45.

4. Wilkoff BL, Love CJ, Byrd CL, et al.; Heart Rhythm Society; American Heart Association. Transvenous lead extraction: Heart Rhythm Society expert consensus on facilities, training, indications, and patient management: this document was endorsed by the American Heart Association (AHA). Heart Rhythm 2009; 6: 1085-104.

5. Kolodzinska K, Kutarski A, Grabowski M, Jarzyna I, Małecka B, Opolski G. Abrasions of the outer silicone insulation of endocardial leads in their intracardiac part: a new mechanism of lead-dependent endocarditis. Europace 2012; 14: 903-10.

6. Bardy GH, Smith WM, Hood MA, et al. An entirely subcutaneous implantable cardioverter-defibrillator. N Engl J Med 2010; 363: 36-44.

7. McLeod CJ, Boersma L, Okamura H, Friedman PA. The subcutaneous implantable cardioverter defibrillator: state-of-the-art review. Eur Heart J 2017; 38: 247-57.

8. Kaczmarek K, Zwoliński R, Bartczak K, Ptaszyński P, Wranicz JK. A subcutaneous implantable cardioverterdefibrillator - the first implantation in Poland. Kardiol Pol 2015; 73: 62 .

9. Kaczmarek KA, Winter J, Wranicz JK, Ptaszyński PA. Atypical position of subcutaneous cardioverter-defibrillator as a solution in hypertrophic cardiomyopathy patient with initially negative electrocardiographic screening. Eur Heart J 2015; 36: 2542.

10. Ponikowski P, Voors AA, Anker SD, et al.; ESC Scientific Document Group. 2016 ESC Guidelines for the diagnosis and treatment of acute and chronic heart failure: the Task Force for the diagnosis and treatment of acute and chronic heart failure of the European Society of Cardiology (ESC)Developed with the special contribution of the Heart Failure Association (HFA) of the ESC. Eur Heart J 2016; 37: 2129-200.

11. Ezzat VA, Lee $V$ Ahsan $S$, et al. A systematic review of ICD complications in randomised controlled trials versus registries: is our 'real-world' data an underestimation? Open Heart 2015; 2: e000198.

12. Ranasinghe I, Parzynski CS, Freeman JV, et al. Long-term risk for device-related complications and reoperations after implantable cardioverter-defibrillator implantation: an observational cohort study. Ann Intern Med 2016; doi: 10.7326/M15-2732 [In press].

13. Bettin $M$, Rath B, Ellermann, et al. Follow-up of the first patients with totally subcutaneous ICD in Germany from implantation till battery depletion. Clin Res Cardiol 2019; 108: 16-21.

14. Köbe J, Reinke F, Meyer C, et al. Implantation and follow-up of totally subcutaneous versus conventional im- 
plantable cardioverter-defibrillators: a multicenter casecontrol study. Heart Rhythm 2013; 10: 29-36.

15. Burke MC, Gold MR, Knight BP, et al. Safety and efficacy of the totally subcutaneous implantable defibrillator: 2-year results from a pooled analysis of the IDE Study and EFFORTLESS Registry. J Am Coll Cardiol 2015; 65: 1605-15.

16. Lewis GF, Gold MR. Safety and efficacy of the subcutaneous implantable defibrillator. J Am Coll Cardiol 2016; 67: 445-54.

17. Olde Nordkamp LR, Knops RE, Bardy GH, et al. Rationale and design of the PRAETORIAN trial: a Prospective, RAndomizEd comparison of subcuTaneOus and tRansvenous ImplANtable cardioverter-defibrillator therapy. Am Heart J 2012; 163: 753-60.e2.

18. Boveda S, Lenarczyk R, Haugaa K, et al. Implantation of subcutaneous implantable cardioverter defibrillators in Europe: results of the European Heart Rhythm Association survey. Europace 2016; 18: 1434-9.

19. Brouwer TF, Yilmaz D, Lindeboom R, et al. Long-term clinical outcomes of subcutaneous versus transvenous implantable defibrillator therapy. J Am Coll Cardiol 2016; 68: 2047-55.

20. Khazen C, Magnusson P, Flandorfer J, Schukro C. The subcutaneous implantable cardioverter-defibrillator: a tertiary center experience. Cardiol J 2018; doi: 10.5603/ CJ.a2018.0050 [In press].

21. Olde Nordkamp LR, Dabiri Abkenari L, Boersma LV, et al. The entirely subcutaneous implantable cardioverterdefibrillator: initial clinical experience in a large Dutch cohort. J Am Coll Cardiol 2012; 60: 1933-9.

22. Dabiri Abkenari L, Theuns DA, Valk SD, et al. Clinical experience with a novel subcutaneous implantable defibrillator system in a single center. Clin Res Cardiol 2011; 100: 737-44.

23. Jarman JW, Todd DM. United Kingdom national experience of entirely subcutaneous implantable cardioverter-defibrillator technology: important lessons to learn. Europace 2013; 15: 1158-65.

24. Bettin M, Larbig R, Rath B, et al. Long-term experience with the subcutaneous implantable cardioverter-defibrillator in teenagers and young adults. JACC Clin Electrophysiol 2017; 3: 1499-506.

25. Brouwer TF, Miller MA, Quast AB, et al. Implantation of the subcutaneous implantable cardioverter-defibrillator: an evaluation of 4 implantation techniques. Circ Arrhythm Electrophysiol 2017; 10: e004663.

26. Jędrzejczyk-Patej E, Boveda S, Kalarus Z, et al. Factors determining the choice between subcutaneous or transvenous implantable cardioverter-defibrillators in Poland in comparison with other European countries a sub-study of the European Heart Rhythm Association prospective survey. Kardiol Pol 2018; 76: 1507-15.

27. Winter J, Siekiera M, Shin DI, et al. Intermuscular technique for implantation of the subcutaneous implantable cardioverter defibrillator: long-term performance and complications. Europace 2017; 19: 2036-41.

28. Lambiase PD, Srinivasan NT. Early experience with the subcutaneous ICD. Curr Cardiol Rep 2014; 16: 516.

29. Lambiase PD, Barr C, Theuns DA, et al.; EFFORTLESS Investigators. Worldwide experience with a totally subcutaneous implantable defibrillator: early results from the EFFORTLESS S-ICD Registry. Eur Heart J 2014; 35: 1657-65.

30. Knops RE, Olde Nordkamp LR, de Groot JR, Wilde AA. Two-incision technique for implantation of the subcutaneous implantable cardioverter-defibrillator. Heart Rhythm 2013; 10: 1240-3.
31. Aydin A, Hartel F, Schlüter M, et al. Shock efficacy of subcutaneous implantable cardioverter-defibrillator for prevention of sudden cardiac death: initial multicenter experience. Circ Arrhythm Electrophysiol 2012; 5: 913-9.

32. Kempa M, Budrejko S, Raczak G. Subcutaneous implantable cardioverter-defibrillator (S-ICD) for secondary prevention of sudden cardiac death. Arch Med Sci 2016; 12: 1179-80.

33. Kempa M, Budrejko S, Sławiński G, et al. Polish singlecentre follow-up of subcutaneous implantable cardioverter-defibrillator (S-ICD) systems implanted for the prevention of sudden cardiac death. Kardiol Pol 2018; 76: 452-8.

34. Grabowski M, Gawałko M, Michalak M, et al. Initial experience with the subcutaneous implantable cardioverter-defibrillator with the real costs of hospitalization analysis in a single Polish center. Cardiol J 2018; doi: 10.5603/CJ.a2018.0024 [In press].

35. Ptaszyński P, Grabowski M, Kowalski O, et al. Subcutaneous implantable cardioverter-defibrillator in prevention of sudden cardiac death in Poland - opinion paper endorsed by the Polish Cardiac Society Working Group on Heart Rhythm. Kardiol Pol 2017; 75: 1057-60. 